\title{
PERBANDINGAN EFEKTIVITAS SIKAT GIGI KONVENSIONAL DENGAN SIKAT GIGI KHUSUS ORTODONTI TERHADAP PENURUNAN INDEKS PLAK PADA PEMAKAI PIRANTI ORTODONTI CEKAT MENGGUNAKAN METODE CHARTER
}

\author{
Ingrid Panbara1, Kuswardani Susari Putri ${ }^{2}$, Kosno Suprianto 1 \\ ${ }^{1}$ Faculty of Dentistry Andalas University \\ ${ }^{2}$ Departemen of Periodontia Faculty of Dentistry Andalas University
}

\begin{abstract}
Background: Component fixed orthodontic appliance that attaches tooth surface can increase the accumulation of plaque. The most simple and effective way to control plaque is tooth brushing. Manual toothbrush which is straight, straight brush handle with the brush head and bristles panel is recommended by the healthy department of Indonesia. Orthodontic toothbrush is designed specifically to eliminate plaque around the brackets. Charter methods is recommended for patient using fixed orthodontic appliance.

Purpose: To determine the effectiveness of conventional toothbrush and orthodontic toothbrush in reducing average plaque index patient using fixed orthodontic appliance with Charter method.

Methods: The research method was experimental with pre and posttest design. The study subjects were 30 people who were

divided into two groups, 15 people usedconventional toothbrushes and 15 people usedorthodontic toothbrushes. Orthodontic

Plaque Index (OPI) was used as plaque index in this research. Analysis of data was using T-test.

Results: Pretest and posttest plaque index of conventional toothbrush were 70,94 and 40,20. Pretest and posttest plaque index of orthodontic toothbrush were 65,59 and 23,74. The average difference in pretest and posttest plaque index of conventional toothbrush was 30,74 and orthodontic toothbrush was 41,84. The result was tested by using independent $t$-test and produced a significant value ( $P$ value) of 0,001

Conclusion: The use of orthodontic toothbrush with Charter method is more effective than conventional toothbrush in removing plaque.
\end{abstract}

Keywords: Plaque index, conventional toothbrush, orthodontic toothbrush

Affiliasi penulis : 1. Fakultas Kedokteran Gigi

Universitas Andalas, 2. Fakultas Kedokteran

Universitas Andalas

Korespondensi: Ingrid Panbara, email:

ingridpanbara@gmail.com Telp:085762003763

\section{PENDAHULUAN}

Pemakaian piranti ortodonti cekat saat ini semakin banyak digunakan di masyarakat, apalagi di kalangan anak-anak dan remaja.Perawatan ortodonti merupakan perawatan di bidang kedokteran gigi yang selain bertujuan memperbaiki maloklusi, juga untuk meningkatkan kesehatan gigi dan mulut, fungsi mastikasi, fungsi bicara dan estetika. ${ }^{1}$ Piranti ortodonti terdiri dari dua macam yaitu piranti ortodonti cekat dan piranti ortodonti lepasan. Piranti ortodonti cekat memiliki desain yang lebih sulit untuk dibersihkan dibandingkan dengan alat piranti lepasan, sehingga pasien pengguna piranti ortodonti cekat lebih sulit untuk memelihara kebersihan mulut selama perawatan). ${ }^{2}$ 
Perawatan ortodonti khususnya penggunaan piranti cekat dengan komponen brackets, arch wires dan komponen lainnya memiliki bentuk yang rumit sehingga mempermudah melekatnya plak lebih lama dan dapat meningkatkan resiko karies, gingivitis, dan kemungkinan terjadi penyakit periodontal. ${ }^{3}$ Plak dapat diartikan sebagai deposit lunak yang membentuk biofilm, melekat pada permukaan gigi atau permukaan kasar lain di dalam rongga mulut termasuk pada restorasi lepasan atau cekat. Apabila plak bercampur dengan zat gula yang ada dalam makanan yang dimakan, maka akan mengakibatkan terbentuknya asam. Asam yang berada dirongga mulut dalam jangka waktu yang lama dengan derajat keasaman yang tinggi, akan memudahkan plak merusak jaringan keras gigi yang mengakibatkan terjadinya demineralisasi permukaan email dan munculnya lesi karies. ${ }^{4}$

Kontrol plak dapat dilakukan secara mekanis dan kimiawi. Cara mekanis yang paling sederhana dan efektif adalah dengan menggosok gigi menggunakan pasta gigi. ${ }^{1}$ Jenis-jenis sikat gigi ada yang manual, elektrik dan sikat gigi khusus untuk pemakai fixed orthodontic. Departemen Kesehatan RI menganjurkan agar memakai sikat gigi manual yang berbentuk lurus, pegangan sikat lurus segaris dengan kepala sikat serta bulu-bulu sikat rata atau datar. Sikat gigi dengan bentuk lurus efektif dalam pembersihan plak. $^{5}$ Pemakai alat ortodonti cekat dianjurkan untuk memakai sikat gigi desain khusus yaitu baris tengah bulu sikat lebih pendek dibanding bulu sikat pada ke dua pinggirnya untuk membantu penyingkiran plak pada bracket. $^{6}$ Hal yang perlu diperhatikan dalam menyikat gigi adalah metode menyikat gigi, beberapa ahli telah menciptakan berbagai metode penyikatan gigi dengan sikat gigi manual yang telah dikembangkan sesuai indikasi masingmasing keadaan. ${ }^{7}$

Menurut Donna Pratiwi (2009) teknik menyikat gigi dengan metode Charter baik untuk membersihkan plak di daerah sela-sela gigi, pada pasien yang memakai fixed orthodontic dan pada pasien dengan gigi tiruan permanen. ${ }^{8}$ Diantara sekian banyak teknik penyikatan gigi yang dilakukan pada pembersihan interdental, metode Charter masih paling efisien menurut para ahli. ${ }^{9}$ Teknik penyikatan pada metode Charter ini dimana pada permukaan bukal dan labial, sikat dipegang dengan tangkai dalam kedudukan horizontal. Ujung-ujung bulu sikat diletakkan pada enamel gigi dan jaringan gingiva dengan bulu membentuk sudut $45^{\circ}$ ke arah permukaan oklusal. Tekanan lateral dan ke bawah kemudian beri getaran lembut dengan pegangan bergerak maju mundur $1 \mathrm{~mm}$ atau lebih. ${ }^{10}$ 
Berdasarkan hasil penelitian Z Rafe (2006) dalam penelitiannya menunjukan perbedaan antara penggunaan sikat gigi ortodonti dengan sikat gigi konvensional terhadap penurunan plak tidak begitu signifikan. $^{11}$ Sedangkan menurut hasil penelitian Sukmawaty tahun 2011 didapatkan hasil bahwa terdapat perbedaan penurunan indeks plak antara pengguna sikat gigi konvensional dengan sikat gigi khusus pada pengguna fixed orthodontic. ${ }^{6}$ Berdasarkan uraian di atas, maka peneliti merasa perlu melakukan penelitian lebih lanjut mengenai efek pembersihan plak dengan membandingkan sikat gigi konvensional dengan sikat gigi khusus ortodonti terhadap efektivitasnya dalam meghilangkan plak.

\section{METODE}

Desain penelitian ini adalah penelitian eksperimental klinis dengan menggunakan metode Pretest and Postest design. Penelitian dilakukan di Fakultas Kedokteran Gigi Universitas Andalas dengan jumlah sampel 30 orang yang dibagi menjadi 2 kelompok. Kelompok I menggunakan sikat gigi konvensional berjumlah 15 orang dan kelompok II menggunakan sikat gigi khusus ortodonti berjumlah 15 orang. Kriteria ekslusi adalah: (1) mengalami karies pada gigi yang diperiksa, (2) adanya kalkulus pada gigi yang diperiksa, (3) memakai piranti ortodonti cekat $<6$ bulan.
Pengambilan data skor plak dilakukan jam 12.00 WIB. Sebelum nya jam 07.00 WIB sampel evaluasi cara menyikat gigi Charter dan diberikan makanan oleh peneliti. Sebelum dilakukan pemeriksaan indeks plak sampel diminta berkumur-kumur untuk menyingkirkan sisa-sisa makanan atau debris. Kemudian seluruh permukaan gigi diolesi dengan disclosing solution, lalu diperiksa bagian yang berwarna. Pemeriksaan dilakukan pada gigi yang ditempati bracket dengan menggunakan perhitungan OPI (orthodontic plaque index).

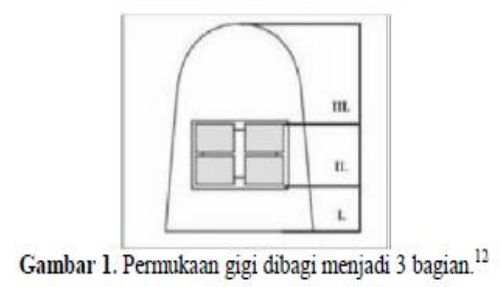

Setiap daerah dan sisi pengukuran memiliki nilai yangberbeda-beda, yaitu: ${ }^{12}$ $1=$ terdapat plak pada bagian oklusal atau insisal daribracket

2 = terdapat plak bagian servikal gigi dari bracket

3 = terdapat plak pada bagian sentral yaitu bagian mesialdan distal dari bracket yang ditutupi kawat

Nilai-nilai tersebut di masukkan kedalam sebuah tabelyang telah tersedia sebagai berikut : 
Tabel 1. Tabel pengukuran indek plak ortodonti ${ }^{12}$

Tabel 1. Tabel pengukuran indek plak ortodonti.
\begin{tabular}{|l|c|c|c|c|c|c|c|c|c|c|c|c|c|c|}
\hline Servikal & 2 & & & & & & & & & & & & & Total \\
\hline Sentral & 3 & & & & & & & & & & & & & Total \\
\hline Okhusal & 1 & & & & & & & & & & & & & Total \\
\hline & & 6 & 5 & 4 & 3 & 2 & 1 & 1 & 2 & 3 & 4 & 5 & 6 & \\
\hline Okhisal & 1 & & & & & & & & & & & & & Total \\
\hline Senrral & 3 & & & & & & & & & & & & & Total \\
\hline Servikal & 2 & & & & & & & & & & & & & Total \\
\hline
\end{tabular}

Nilai pemeriksaan pada pasien dimasukkan kedalam tabel dengan tanda $(\sqrt{ })$ jika terdapat plak. Kemudian penghitungan indeks plak individu dihitung dengan rumus :

$\mathrm{OPI} \%=\frac{\text { Jumlah nilai dari setiap gigi yang diperiksa }}{\text { Jumlah gigi yang diperiksa } \mathrm{X} 6}$

Setelah dilakukan pemeriksaan indeks plak sebelum menyikat gigi, sampel pada kedua kelompok diinstruksikan untuk menyikat gigi selama 2 menit menggunakan metode Charter. Setelah itu diolesi lagi disclosing solution dan diukur dengan indeks plak yang sama.

Dilakukan uji statistik independent T-test untuk mengetahui perbedaan penurunan indeks plak antara sikat gigi konvensional dan sikat gigi khusus ortodonti.

\section{HASIL}

Responden yang mengikuti penelitian berusia 18 tahun sampai 22 tahun, dari 30 orang responden penelitian, umur responden terbanyak berumur 21 tahun yaitu sebanyak 11 orang $(36,7 \%)$ dan paling sedikit berumur 22 tahun yaitu sebanyak 2 orang (6,7\%), (Gambar 2).

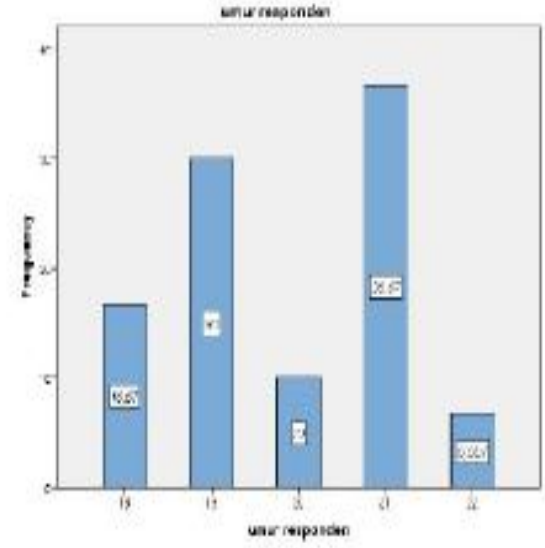

Gambar 2. Distribusi responden berdasarkan umur

Sebagian besar jenis kelamin responden dalam penelitian ini adalah perempuan sebanyak 29 orang $(96,7 \%)$ dan laki-laki 1 orang $(3,3 \%)$, (Gambar 3$)$.

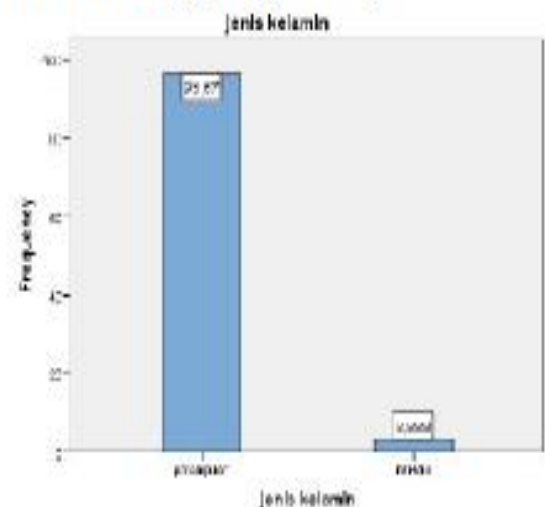

Gambar 3. Distribusi responden berdasarkan jenis kelamin

Lama pemakaian piranti ortodonti cekat terbanyak adalah 3 tahun, yaitu sebanyak $16,7 \%$, (Gambar 4).

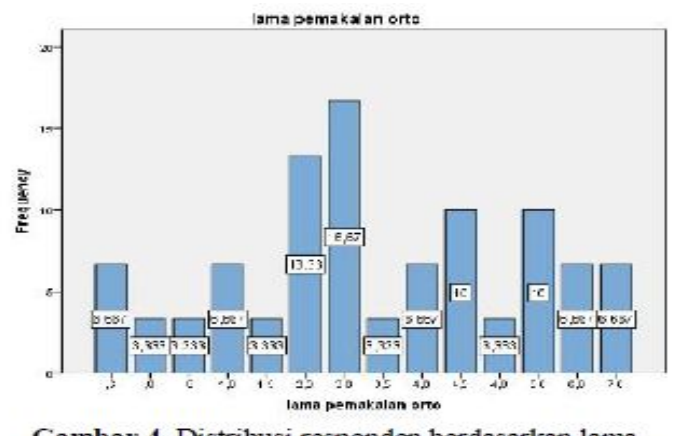

Gambar 4. Distribusi responden berdasarkan lama pemakaian piranti ortodonti cekat

Hasil penelitian menunjukkan adanya perbedaan yang signifikan rerata skor 
indeks plak sebelum dan sesudah menyikat gigi, baik pada kelompok sikat gigi konvensional dan sikat gigi khusus ortodonti $(\mathrm{p}<0,05)($ tabel 2).

Tabel 2. Hasil uji statistik indeks plak sebelum dan sesudah menyikat gigi

\begin{tabular}{ccccc}
\hline \multirow{2}{*}{$\begin{array}{c}\text { Kelompok } \\
\text { sikat gigi }\end{array}$} & $\mathrm{N}$ & \multicolumn{2}{c}{ Rerata indeks plak $(\mathrm{X} \pm \mathrm{SD})$} & \multirow{2}{*}{$\mathrm{p}$} \\
\cline { 4 - 5 } \cline { 4 - 5 } $\begin{array}{c}\text { Konvensional } \\
\text { Khusus }\end{array}$ & 15 & $70,94 \pm 19,06$ & $40,20 \pm 17,68$ & 0,000 \\
Knnnnn & 15 & $65,59 \pm 15,33$ & $23,74 \pm 12,79$ & 0,000 \\
\hline
\end{tabular}

Hasil analisis dengan uji statistik independent $\mathrm{t}$-test menunjukkan adanya perbedaan penurunan indeks plak yang bermakna $(\mathrm{p}<0,05)$ pada pemakai piranti ortodonti cekat yang menggunakan sikat gigi khusus ortodonti dan sikat gigi konvensional (Tabel 3).

Tabel 3. Hasil uji statistik penurunan indeks plak sikat gigi khusus ortodonti dan sikat gigi konvensional

\begin{tabular}{cccc}
\hline $\begin{array}{c}\text { Kelonpok } \\
\text { sikat gigi }\end{array}$ & $\mathrm{N}$ & $\begin{array}{c}\text { Penurunan indeks plak } \\
(\mathrm{X} \pm \mathrm{SD})\end{array}$ & $\mathrm{p}$ \\
\hline $\begin{array}{c}\text { Konvensional } \\
\text { Khusus }\end{array}$ & 15 & $30,74 \pm 7,46$ & 0,001 \\
& 15 & $41,84 \pm 8,75$ & \\
\hline
\end{tabular}

\section{PEMBAHASAN}

Skor rerata penurunan indeks plak kelompok sikat gigi khusus ortodonti $(41,84)$ lebih besar dibandingkan kelompok sikat gigi konvensional $(30,74)$ artinya penurunan idneks plak kelompok sikat gigi khusus ortodonti lebih efektif dengan nilai $\mathrm{p}=0,001$. Hal ini mungkin karena desain bulu sikat gigi khusus ortodonti memiliki ketinggian bulu yang bervariasi sehingga dapat menjangkau dan menyesuaikan keadaan permukaan gigi yang ditempati bracket. ${ }^{13}$ Aksinya saat menyikat gigi tidak terhalangi oleh bracket yang menempel pada permukaan gigi karena desain sikat gigi yang berbentuk $V$-shape dapat memasuki interdental gigi dan tidak memberikan kekakuan saat digunakan. Berbeda halnya dengan sikat gigi konvensional yang memiliki desain permukaan bulu sikat datar membuat sikat ini sulit untuk menjangkau bagian interdental gigi karena terhalang oleh bracket. $^{6}$

Efektivitas menyikat gigi juga dipengaruhi oleh metode menyikat gigi yang digunakan. Salah satu metode yangdianjurkan untuk dipakai oleh pemakai piranti ortodonti cekat adalah metode Charter. Metode ini efektif untuk membersihkan bagian di sekitar bracket, namun untuk bagian insisal/oklusal dari bracket masih ada sedikit perwarnaan, karena bulu sikat gigi ditempatkan pada sudut kurang lebih 450 terhadap sumbu panjang gigi ke arah oklusal dengan memberikan getaran disertai gerakan rotasi kecil sehingga masih terdapat plak pada bagian insisal/oklusal.

Hasil penelitian ini mendukung hasil penelitian oleh Sukmawaty tahun 2011 mengenai efek sikat gigi konvensional dan sikat gigi ortodonti dalam penurunan indeks plak pasien ortodonti cekat. Indeks plak yang digunakan adalah indeks plak PHP oleh Podshadley dan Haley dan 
metode menyikat gigi yang dipakai adalah metode yang biasa dipakai subyek seharihari tanpa ada pemberian perlakuan yang sama mengenai metode menyikat gigi yang digunakan salam penelitian. Dalam menyikat gigi dengan sikat gigi khusus ortodonti dapat memberikan efek penurunan plak yang signifikan pada pemakai piranti ortodonti cekat yaitu 2,46. Selisih indeks plak pada kelompok sikat gigi khusus ortodonti adalah 2,96 dan kelompok sikat gigi konvensional adalah 2,07 .

\section{KEPUSTAKAAN}

1. Dewi S.A, Jazaldi F, Soegiharto B.M. Herbal and Conventional Toothpastes Roles in Gingivitis Control in Orthodontic Patients. Journal of Dentistry Ind,2011: 68 -72 .

2. Singh G. Fixed orthodontic appliances. In: Singh G,editor. Text Book of Orthodontics (Second Edition).New Delhi: Jaypee Publishers, 2007; p.449

3. Marinia I, Bortolottib F, Parentic SI, Gattod MR,Bonettid GA. "Combined effects of repeated oral

1. hygiene motivation and type of tootbrush onorthodontic patients". Angle Orthodontist. 2014.

4. Hamsar A. Perbandingan sikat gigi yang berbuluhalus (soft) dengan sikat gigi yang berbulu sedang (medium) terhadap manfaatnya menghilangkan plak pada anak usia 9-12 tahun di SD Negeri 060830 Kecamatan Medan Petisah. Jurnal Ilmiah PANNMED; 2005: 20-23.
5. Sriyono, N.W. Perbedaan efektivitas sikat gigi manual dengan sikat gigi listrik dan lamanya menyikat gigi dalam pembersihan plak. Dentika Dental Journal, 2006, vol.11, no 1 , hlm. 20-25

6. Sukmawaty, W. Efektivitas Sikat Gigi Konvensional dan Sikat Gigi Khusus Orthodonti Terhadap

2. penurunan Indeks plak pasien ortodonti piranti cekat. Dentika Dental Journal; 2011, 16(1): 16-17

7. Daliemunthe SH. Terapi periodontal. Medan: Departemen Periodonsia Fakultas Kedokteran Gigi

3. Universitas Sumatera Utara. 2006.

8. Pratiwi, Dona. Gigi sehat dan cantik. Jakarta: Kompas, 2009: 67-8

9. Putri M.H., Herijulianti E., Nurjannah N. Ilmu pencegahan penyakit jaringan keras dan jaringan

4. pendukung gigi. Jakarta: EGC. 2010.

10. Roth H., Thaller J., Alderman N. E. The Charters method of tootbrush massage: a valuable supplement in periodontal therapy. The Journal of Periodontology. New York.

11. Rafe Z. Comparativee study of 3 type of toothbrushes in patients with fixed orthodontic appliance. American Journal of Orthodontic and Dentofacial Orthopedics; 2006, 130(1): 92-95.

12. Ticha $\mathrm{R}$, Bohmova $\mathrm{H}$. Influence offixed orthodontic appliance on the level of patients oral hygiene. Odborna Prace; 2005, 14(4): 29-31.

13. Darby M.L, Walsh M.M. Dental Hygiene Theory And Practice 3nd Edition. Elsevier. Philadelphia. 2010. 